\title{
Interventional radiology for liver diseases
}

\author{
Luc Defreyne ${ }^{1}$ (D)
}

Received: 26 July 2020 / Accepted: 25 September 2020 / Published online: 3 October 2020

(C) European Society of Radiology 2020

Over the past thirty years interventional radiology of the liver has evolved tremendously. Established as portal vein decompression and tumor treatment, IR technology advanced continuously. Covered ePTFE stents significantly increased TIPS patency and ascites control $[1,2]$. ePTFE-covered stents were tested in percutaneous palliation of biliary malignancies to prevent tumor ingrowth and increase patency. Randomized controlled trials (RCT) endorsed covered stents in extrahepatic bile duct malignancies [3]. For intrahepatic biliary malignancies, ePTFE-covered stents worked but failed to fulfill their promise: sludge formation on the inner coating impedes longer patency times [4]. Long-term patency of stents becomes a major issue, as progress in medical treatment offers longer live expectancy for patients with, i.e., portal hypertension, Budd-Chiari disease, biliary strictures, or malignancies. Research projects on drug-eluting stents and radioactive or resorbable stents are ongoing [5, 6]. Although metallic stents have been put aside in benign biliary strictures in favor of repeat balloon dilatation, preliminary results with a biodegradable stent are promising [7, 8].

Conventional chemoembolization (cTACE) and radiofrequency ablation (RFA) were embedded in the Barcelona Classification of Liver Cancer (BCLC), remaining unchallenged as level I treatments for intermediate and early HCC for almost twenty years [9-13]. However, cTACE suffers from drug and dose variation as well as technical permutations. The drug-eluting beads (DEB-TACE, Boston Scientific) installed standardization of chemoembolization, proving efficacy but not yet superiority over cTACE [14-16]. Because of a lower post-embolization toxicity, DEB-TACE research was continued with emerging of eluting microspheres manufactured from polyvinyl alcohol (CalliSpheres, Jiangsu Hengrui), expanding trisacryl/gelatin

Luc Defreyne

Luc.Defreyne@ugent.be

1 Department of Interventional Radiology, University Hospital of Ghent, Ghent University, C. Heymanslaan 10, B-9000 Ghent, Belgium
(HepaSphere or QuadraSphere, Merit Medical), polyethylene glycol (LifePearl, Terumo), and hydrogel with polyzene coating (Tandem, Varian). All DEB-TACE beads are nonresorbable agents, permanently blocking tumor supply at different levels according to bead sizes (from 500 to $40 \mu$ ) [17-20]. As tumor response did not quite differ, the question remains whether the eluting chemotherapeutic or the embolic particulate dominates the anti-tumor effect. Interestingly, degradable starch microspheres combined with a chemotherapeutic are finding their way into clinical practice, even in advanced HCC [21]. Biodegradable microspheres are captivating with a range of "biogel" materials now under investigation [22]. First in queue for clinical testing are combined degradable and drug-eluting beads (BioPearl, Terumo), which might provide more insight into the anti-tumoral mode of action.

Innovations in bead delivery such as radiopaque beads (DC Bead LUMI), beads in combination with Lipiodol or steerable microcatheters (swingNINA $®$, Merit), anti-reflux mechanism (Surefire, TriSalus Life Science; SeQure, Guerbet), or underpressure inducing balloon microcatheter (Occlusafe, Terumo) increase safety but impact on tumor response is still investigational [23-26]. Intriguing for the future are composite microbeads, made of magnetic nanoparticles and polymeric matrix microspheres that may induce tumor ablation effects upon application of alternating magnetic field [27].

Despite the huge experience with Y90 in HCC, modern transarterial radioembolization (TARE) still struggles to enter the BCLC classification [28]. The FDA only approved TARE as neoadjuvant for surgery or liver transplantation or in advanced stage with PVT [28]. Further promotion is not yet under discussion because powerful RCTs comparing Y90 with cTACE or its equivalent DEB-TACE are lacking [29-31]. The TRACE trial was halted at interim analysis because of significant improved time to tumor progression and overall survival (OS) with TARE (versus DEB-TACE). The trial missed its public premiere at SIR congress 2020, canceled by the COVID-19 pandemic [32]. Salem et al purposefully give a shot across the bows reporting their hospital HCC board 
had decided to adapt TARE as first-line locoregional treatment of liver-limited HCC [33].

Why is it so onerous to conduct a large RCT in locoregional HCC treatment? Patient accrual within one BCLC class is well-known slowly. Raising funds for a multicentric RCT to investigate expensive commercial particles for locoregional HCC treatment is a desperate job. But when to compare with a systemic tyrosine kinase inhibitor and to prove superiority of TARE, then company funding is attainable. Unfortunately, three large RCTs comparing TARE versus sorafenib $[34,35]$ and TARE plus sorafenib versus sorafenib alone [36] failed the endpoint of OS superiority of TARE. Combining these RCTs, a company-sponsored metaanalysis sublimed a non-inferiority of TARE for advanced HCC to sorafenib in terms of OS combined with a better safety profile [37]. Will this conclusion be enough to change the FDA's mind? Or will we have to wait until novel tyrosine inhibitors and immune check point inhibitors enter the competition, eventually opposing the latest TARE variant, Holmium-166 [38, 39]?

For colorectal liver metastasis (mCRC), TARE was a great hope to grant patients a "chemo-holiday" and eventually improve outcome. However, there is no evidence that chemotherapy with resin Y90 TARE improves OS or quality of life $[40,41]$. Whether the glass Y90, with less particles but higher activity per bead, will turn the tables for TARE in second line for mCRC will be revealed soon [42].

Established IR solutions are challenged by innovations in endoscopy (i.e., percutaneous versus echo-endo biliary stenting), surgery (i.e., portal vein embolization versus ALLPS), or even systemic treatments [43]. Competition, research, and collaboration should keep IR in the front line for delivery of future pharmacology such as radio- and nanoparticles or modified virus or other immunotherapy. Portal and hepatic vein research, whether for implantation of I125 seeds in tumorous occlusion, as entry for autotransplantation of islet cell, as part of percutaneous hepatic perfusion (chemosaturation) or to increase safety of hepatectomy should receive full attention [44-47]. Extending angiography by cone beam or hybrid angio-CT systems with image fusion, combined with high frequency jet ventilation should keep IR in pole position for efficient and safe tumor ablation [48-51]. Cost-effectiveness studies combining quality of life and/or treatment outcome should increase acceptance of IR, even if "willingness to pay" is heavily dependent on one country's health policy [52-54]. Finally, IR should contemplate not only on trial protocols comparing locoregional treatments but also disclose and publish existing data to avoid futile research and underreporting [55].

Funding The authors state that this work has not received any funding.

\section{Compliance with ethical standards}

Guarantor The scientific guarantor of this publication is Luc Defreyne.

Conflict of interest The authors of this manuscript declare no relationships with any companies whose products or services may be related to the subject matter of the article.

Statistics and biometry No complex statistical methods were necessary for this paper.

Informed consent Written informed consent was not required for this study because it is an Editorial comment.

Ethical approval Institutional Review Board approval was not required because it is an Editorial comment.

Methodology

- Editorial comment

\section{References}

1. Bureau C, Thabut D, Oberti F et al (2017) Transjugular intrahepatic portosystemic shunts with covered stents increase transplant-free survival of patients with cirrhosis and recurrent ascites. Gastroenterology 152:157-163

2. Geeroms B, Laleman W, Laenen A et al (2017) Expanded polytetrafluoroethylene-covered stent-grafts for transjugular intrahepatic portosystemic shunts in cirrhotic patients: long-term patency and clinical outcome results. Eur Radiol 27:1795-1803

3. Krokidis M, Fanelli F, Orgera G, Bezzi M, Passariello R, Hatzidakis A (2010) Percutaneous treatment of malignant jaundice due to extrahepatic cholangiocarcinoma: covered Viabil stent versus uncovered Wallstents. Cardiovasc Intervent Radiol 33:97-106

4. Dhondt E, Vanlangenhove P, Geboes K, Vandenabeele L, Van Cauwenberghe L, Defreyne L (2020) No evidence of improved efficacy of covered stents over uncovered stents in percutaneous palliation of malignant hilar biliary obstruction: results of a prospective randomized trial. Eur Radiol 30:175-185

5. Mohan BP, Canakis A, Khan SR et al (2020) Drug eluting versus covered metal stents in malignant biliary strictures-is there a clinical benefit?: a systematic review and meta-analysis. J Clin Gastroenterol. https://doi.org/10.1097/MCG.0000000000001377

6. Chen G, Zhang M, Sheng YG et al (2020) Stent with radioactive seeds strand insertion for malignant hilar biliary obstruction. Minim Invasive Ther Allied Technol. https://doi.org/10.1080/13645706. 2020.1735446

7. Dhondt E, Vanlangenhove P, Van Vlierberghe H et al (2019) Benign anastomotic biliary strictures untreatable by ERCP: a novel percutaneous balloon dilatation technique avoiding indwelling catheters. Eur Radiol 29:636-644

8. De Gregorio MA, Criado E, Guirola JA et al (2020) Absorbable stents for treatment of benign biliary strictures: long-term follow-up in the prospective Spanish registry. Eur Radiol. https://doi.org/10. 1007/s00330-020

9. Llovet JM, Real MI, Montaña X et al (2002) Arterial embolisation or chemoembolisation versus symptomatic treatment in patients with unresectable hepatocellular carcinoma: a randomised controlled trial. Lancet 359:1734-1739

10. Lo CM, Ngan H, Tso WK et al (2002) Randomized controlled trial of transarterial lipiodol chemoembolization for unresectable hepatocellular carcinoma. Hepatology 35:1164-1171 
11. Simo KA, Sereika SE, Newton KN, Gerber DA (2011) Laparoscopic-assisted microwave ablation for hepatocellular carcinoma: safety and efficacy in comparison with radiofrequency ablation. J Surg Oncol 104:822-829

12. Cucchetti A, Piscaglia F, Cescon M et al (2014) An explorative data-analysis to support the choice between hepatic resection and radiofrequency ablation in the treatment of hepatocellular carcinoma. Dig Liver Dis 46:257-263

13. Chinnaratha MA, Chuang MA, Fraser RJ, Woodman RJ, Wigg AJ (2016) Percutaneous thermal ablation for primary hepatocellular carcinoma: a systematic review and meta-analysis. J Gastroenterol Hepatol 31:349-354

14. Lammer J, Malagari K, Vogl T et al (2010) Prospective randomized study of doxorubicin-eluting-bead embolization in the treatment of hepatocellular carcinoma: results of the PRECISION V study. Cardiovasc Intervent Radiol 33:41-52

15. Sacco R, Bargellini I, Bertini M et al (2011) Conventional versus doxorubicin-eluting bead transarterial chemoembolization for hepatocellular carcinoma. J Vasc Interv Radiol 22:1545-1552

16. Golfieri R, Giampalma E, Renzulli M et al (2014) Randomised controlled trial of doxorubicin-eluting beads vs conventional chemoembolisation for hepatocellular carcinoma. Br J Cancer 111:255-264

17. Greco G, Cascella T, Facciorusso A et al (2017) Transarterial chemoembolization using $40 \mu \mathrm{m}$ drug eluting beads for hepatocellular carcinoma. World J Radiol 9:245-252

18. Balli H, Aksungur E, Khalatai B, Aikimbaev K (2019) Superselective transarterial chemoembolization with doxorubicinloaded drug-eluting beads sized below and above 100 microns in hepatocellular carcinoma: a comparative study. J Belg Soc Radiol 103:47. https://doi.org/10.5334/jbsr.1841

19. Aal AKA, Moawad S, Lune PV et al (2019) Survival outcomes of very small drug-eluting beads used in chemoembolization of unresectable hepatocellular carcinoma. J Vasc Interv Radiol 30: 1325-1334.e2

20. Malagari K, Moschouris H, Kiakidis T et al (2019) Five-years outcome analysis of 142 consecutive hepatocellular carcinoma patients treated with doxorubicin eluting microspheres $30-60 \mu \mathrm{m}$ : results from a single-centre prospective phase II trial. Cardiovasc Intervent Radiol 42:1551-1562

21. Iezzi R, Pompili M, Rinninella E et al (2019) TACE with degradable starch microspheres (DSM-TACE) as second-line treatment in HCC patients dismissing or ineligible for sorafenib. Eur Radiol 29: 1285-1292

22. Doucet J, Kiri L, O'Connell K et al (2018) Advances in degradable embolic microspheres: a state of the art review. J Funct Biomater 9: $1-24$

23. Reicher J, Mafeld S, Priona G et al (2019) Early experience of transarterial chemo-embolisation for hepatocellular carcinoma with a novel radiopaque bead. Cardiovasc Intervent Radiol 42:1563-1570

24. Caine M, Chung T, Kilpatrick H et al (2019) Evaluation of novel formulations for transarterial chemoembolization: combining elements of Lipiodol emulsions with drug-eluting beads. Theranostics 9:5626-5641

25. Pasciak AS, McElmurray JH, Bourgeois AC, Heidel RE, Bradley YC (2015) The impact of an antireflux catheter on target volume particulate distribution in liver-directed embolotherapy: a pilot study. J Vasc Interv Radiol 26:660-669

26. Rose SC, Halstead GD, Narsinh KH (2017) Pressure-directed embolization of hepatic arteries in a porcine model using a temporary occlusion balloon microcatheter: proof of concept. Cardiovasc Intervent Radiol 40:1769-1776

27. Chen YP, Zhang JL, Zou Y, Wu YL (2019) Recent advances on polymeric beads or hydrogels as embolization agents for improved transcatheter arterial chemoembolization (TACE). Front Chem 7: 408. https://doi.org/10.3389/fchem.2019.00408
28. Vogel A, Saborowski A (2020) Current strategies for the treatment of intermediate and advanced hepatocellular carcinoma. Cancer Treat Rev 82:101946. https://doi.org/10.1016/j.ctrv.2019.101946

29. Salem R, Gordon AC, Mouli S et al (2016) Y 90 radioembolization significantly prolongs time to progression compared with chemoembolization in patients with hepatocellular carcinoma. Gastroenterology 151:1155-1163.e2

30. Kolligs FT, Bilbao JI, Jakobs T et al (2015) Pilot randomized trial of selective internal radiation therapy vs. chemoembolization in unresectable hepatocellular carcinoma. Liver Int 35:1715-1721

31. Pitton MB, Kloeckner R, Ruckes C et al (2015) Randomized comparison of selective internal radiotherapy (SIRT) versus drugeluting bead transarterial chemoembolization (DEB-TACE) for the treatment of hepatocellular carcinoma. Cardiovasc Intervent Radiol 38:352-360

32. Dhondt E, Hermie L, Verhelst X, Lambert B, Defreyne L (2020) Transarterial radioembolization versus drug-eluting beads chemoembolization for treatment of inoperable early and intermediate hepatocellular carcinoma: interim results of the randomized controlled TRACE trial. JVIR 31(3):1-338

33. Salem R, Gabr A, Riaz A et al (2018) Institutional decision to adopt Y 90 as primary treatment for hepatocellular carcinoma informed by a 1,000-patient 15-year experience. Hepatology 68:1429-1440

34. Chow PKH, Gandhi M, Tan SB et al (2018) SIRveNIB: selective internal radiation therapy versus sorafenib in Asia-Pacific patients with hepatocellular carcinoma. J Clin Oncol 36:1913-1921

35. Vilgrain V, Pereira H, Assenat E et al (2017) Efficacy and safety of selective internal radiotherapy with yttrium-90 resin microspheres compared with sorafenib in locally advanced and inoperable hepatocellular carcinoma (SARAH): an open-label randomised controlled phase 3 trial. Lancet Oncol 18:1624-1636

36. Ricke J, Klümpen HJ, Amthauer H et al (2019) Impact of combined selective internal radiation therapy and sorafenib on survival in advanced hepatocellular carcinoma. J Hepatol 71:1164-1174

37. Venerito M, Pech M, Canbay A et al (2020) NEMESIS: non-inferiority, individual patient meta-analysis of selective internal radiation therapy with yttrium-90 resin microspheres versus sorafenib in advanced hepatocellular carcinoma. J Nucl Med. https://doi.org/10. 2967/jnumed.120.242933

38. Kudo M (2019) Targeted and immune therapies for hepatocellular carcinoma: predictions for 2019 and beyond. World J Gastroenterol 25:789-807

39. Radosa CG, Radosa JC, Grosche-Schlee S et al (2019) Holmium166 radioembolization in hepatocellular carcinoma: feasibility and safety of a new treatment option in clinical practice. Cardiovasc Intervent Radiol 42:405-412

40. Wasan HS, Gibbs P, Sharma NK et al (2017) First-line selective internal radiotherapy plus chemotherapy versus chemotherapy alone in patients with liver metastases from colorectal cancer (FOXFIRE, SIRFLOX, and FOXFIRE-Global): a combined analysis of three multicentre, randomised, phase 3 trials. Lancet Oncol 18:1159-1171

41. Wolstenholme J, Fusco F, Gray AM et al (2020) Quality of life in the FOXFIRE, SIRFLOX and FOXFIRE-global randomised trials of selective internal radiotherapy for metastatic colorectal cancer. Int J Cancer 147:1078-1085

42. Chauhan N, Mulcahy MF, Salem R et al (2019) TheraSphere yttrium- 90 glass microspheres combined with chemotherapy versus chemotherapy alone in second-line treatment of patients with metastatic colorectal carcinoma of the liver: protocol for the EPOCH phase 3 randomized clinical trial. JMIR Res Protoc 8:e11545

43. Wu X, Rao J, Zhou X, Deng R, Ma Y (2019) Partial ALPPS versus complete ALPPS for staged hepatectomy. BMC Gastroenterol 19: $170-179$ 
44. Zhang L, Hu B, Li W et al (2020) ${ }^{125}$ I irradiation stent for hepatocellular carcinoma with main portal vein tumor thrombosis: a systematic review. Cardiovasc Intervent Radiol 43:196-203

45. Abu-El-Haija M, Anazawa T, Beilman GJ et al (2020) The role of total pancreatectomy with islet autotransplantation in the treatment of chronic pancreatitis: a report from the international consensus guidelines in chronic pancreatitis. Pancreatology 20:762-771

46. Marquardt S, Kirstein MM, Brüning R et al (2019) Percutaneous hepatic perfusion (chemosaturation) with melphalan in patients with intrahepatic cholangiocarcinoma: European multicentre study on safety, short-term effects and survival. Eur Radiol 29:18821892

47. Guiu B, Quenet F, Escal L et al (2017) Extended liver venous deprivation before major hepatectomy induces marked and very rapid increase in future liver remnant function. Eur Radiol 27: 3343-3352

48. Denys A, Lachenal Y, Duran R, Chollet-Rivier M, Bize P (2014) Use of high-frequency jet ventilation for percutaneous tumor ablation. Cardiovasc Intervent Radiol 37:140-146

49. Lee MW, Kang D, Lim HK et al (2020) Updated 10-year outcomes of percutaneous radiofrequency ablation as first-line therapy for single hepatocellular carcinoma $<3 \mathrm{~cm}$ : emphasis on association of local tumor progression and overall survival. Eur Radiol 30: 2391-2400

50. Worakitsitisatorn A, Lu DS, Lee MW et al (2020) Percutaneous thermal ablation of subcapsular hepatocellular carcinomas: influence of tumor-surface contact and protrusion on therapeutic efficacy and safety. Eur Radiol 30:1813-1821

51. Feng Y, Wu H, Huang DQ et al (2020) Radiofrequency ablation versus repeat resection for recurrent hepatocellular carcinoma $(\leq 5$ $\mathrm{cm})$ after initial curative resection. Eur Radiol. https://doi.org/10. 1007/s00330-020

52. Fateen W, Khan F, O’Neill RJ, James MW, Ryder SD, Aithal GP (2017) Healthcare costs of transarterial chemoembolization in the treatment of hepatocellular carcinoma. J Hepatocell Carcinoma 4: $123-130$

53. Cucchetti A, Piscaglia F, Cescon M et al (2013) Cost-effectiveness of hepatic resection versus percutaneous radiofrequency ablation for early hepatocellular carcinoma. J Hepatol 59:300-307

54. Pollock RF, Colaone F, Guardiola L, Shergill S, Brennan VK (2020) A cost analysis of SIR-Spheres yttrium-90 resin microspheres versus tyrosine kinase inhibitors in the treatment of unresectable hepatocellular carcinoma in France, Italy, Spain and the UK. J Med Econ 23:593-602

55. Grégory J, Créquit P, Vilgrain V, Ronot M, Boutron I (2020) Results of trials assessing transarterial chemoembolization for treating hepatocellular carcinoma are critically underreported. Eur Radiol. https://doi.org/10.1007/s00330-020

Publisher's note Springer Nature remains neutral with regard to jurisdictional claims in published maps and institutional affiliations. 